\title{
On Influencing Factors and Cluster Analysis of the Five-year Oriented University Students' Course Grades
}

\author{
Yanling Liu ${ }^{1, a}$, Liping Wang, \\ 1, First Author Department of Education, Pingxiang College, No.211 Pingan Road, Pingxiang, Jiangxi \\ Province, P.R. China 337055, \\ *2,Corresponding Author Department of Scientific Research, Pingxiang College, No.211 Pingan Road, \\ Pingxiang, Jiangxi Province, P.R. China 337055 \\ a'Yanling_LIU13@163.com,bwlp8631@163.com \\ Corresponding author: Liping Wang（wlp8631@163.com）.
}

Key words: Influencing Factors, SEE, University Course Grades

\begin{abstract}
Teaching quality is the focus of teaching work. Taking five-year oriented students enrolled in 2010 from P University as sample, it explores the relation of students' university grades and Senior Entrance Exam grades. And take on cluster analysis method to study the correlation between grades of university and those in SEE, the grades of all courses and those of SEE.
\end{abstract}

\section{Introduction}

Teaching is one of the core work of colleges and universities. And the teaching quality ,as the focus of teaching work, has always been concerned by the universities, families and educational administrative departments. In the existing models of quantitative analysis, there is no consensus about what kind of evaluation index can truly reflect the quality of teaching. A common practice is to generalize the test scores to all or ideal grades. It is possible to explore the characteristics of students' course grades and their influencing factors ,such as the Senior Entrance Exam (SEE) factor how to affect university students' course grades. It can provide not only a reference for the reform of the basic education, SEE and higher education, but also better college enrollment and students' self improvement.

\section{Previous research}

As a continuation of medium education, university education has been affected by many factors. For oriented university students, the important influence factors is students personal circumstances, personal quality and the situation of test (Lily). Nowadays, there is a growing trend of using the qualitative and quantitative research methods. Taking university students as research objects and follows the working path of "pre-research interview" to "the questionnaire data collection", try to obtain the basic relationship between the factors and explore differences in student achievement at all levels.(Zhao hongxia in 2011)

\section{Conceptual Framework and Hypotheses}

Taking Pingxiang University as an example, it analyzes the correlation of all course grades each semester and directional year of oriented students enrolled in 2010. Clustering method is applied to analyze the influence of SEE grades on university course grades, the relevance of university course 
grades and SEE grades, the relevance of a course grade in university and every course grades in SEE. And discuss thoroughly the characteristics of course grades in university, therefore the rules of influence factors of course grades of the oriented university students.

\section{Methodology}

Taking students enrolled in 2010 from Pingxiang University as sample, mainly analyze their course grades from the first to fifth semester.

Supposed that there are a total of $\mathrm{n}$ students to participate in the examination, and the examination results ranking from high to low, the score $\mathrm{X}$ qualifying as $\mathrm{i}, \mathrm{i}-1$ is the number of grater than $\mathrm{X}$ scores. All the same grades has the same ranking. All course grades in university are evaluated by excellent rate. When it is necessary to consider multi course grades, these excellence rates weighted sum will be used as evaluation index. And the weight is the course credit. According to the definition above, total score of a semester is: excellence rates weighted sum of all courses this term. And weight is the course credits.

\section{Results}

The correlation between grades of university and those in SEE. The relationship of the Chinese grades of SEE and those of various semesters in university. In order to perform factor analysis on the relationship of course grades in university each semester and grades in SEE, it is necessary to transform all grades in SEE as the ratio of the actual grades and full marks and calculate the correlation coefficient matrix after the standardization of all results. Table 1 The correlation coefficient of grades of each semester

\begin{tabular}{|c|c|c|c|c|c|}
\hline & The first semester & The second semester & The third semester & The fourth semester & The fifth semester \\
\hline The first semeste & 1.000 & 0.746 & 0.672 & 0.608 & 0.366 \\
\hline The second semester & 0.746 & 1.000 & 0.766 & 0.711 & 0.435 \\
\hline The third semester & 0.672 & 0.766 & 1.000 & 0.801 & 0.496 \\
\hline The fourth semester & 0.608 & 0.711 & 0.801 & 0.730 & 0.578 \\
\hline The fifth semester & 0.366 & 0.435 & 0.496 & 0.578 & 1.000 \\
\hline
\end{tabular}

The relationship of Math, English and comprehensive grades in SEE and course grades of each university semeste. We select 3 factors because the cumulative contribution rate of the first 3 factors is more than $8 \%$, and no variable loss in the factor load matrix by calculating the normalized correlation coefficient matrix. Then carry out the factor rotation in order to clarify the meaning of each factor. From absolute value of correlation coefficient between the factors and the variables we can know that factor 1 has higher correlation with the first few college semesters. It is described as pre course grades. Similarly, factor 2 can be described as latter course grades in university. And factor 3 stand for the course grades in SEE. From the correlation coefficient between factor 1 and single course grades in SEE, the pre college grades will be affected by single course grades in SEE.

The correlation between the grades of all courses and those of SEE. Analysis on the performance characteristics of various types of courses. Similar to the previous analysis, we carry on factor analysis on the grades of public basic course (Class A), basic disciplinary courses (Class B) and professional class (Class C) of students enrolled in 2010, who have such complete information and total 92. Coefficient matrix can determine the final number of factors 2 (cumulative 
contribution rate of the first two factors reached 94.634\%) according to the characteristics of the calculated correlation. And rotate each factor in order to clear their meaning. The rotated factor loading vector shows, factor 1 stand for the grades of class A and part of B class grades, of which the main is an A-level grades, called basic grades. And factor 2 stand for the grades of class $\mathrm{C}$ and part of class B, called professional grades. The results of factor analysis show that these three kinds of courses are related to each other as they are in the different levels of the complete curriculum system. Relatively speaking, there exists a high degree of commonality between the professional courses and basic disciplinary courses and great difference between the professional courses and public basic courses. Basic disciplinary courses is the transition of public basic courses and professional courses, and have a certain degree of commonality with these two kinds of courses. It shows that grades of these three courses are not affected by Chinese grades in SEE. This conclusion is consistent with the analysis above. In other factor analysis, when the number of factors is equal to 3 , the original information can be reflected more than $95 \%$.

All factor 1 and factor 2 can still be described as basic and professional grades. And factor 3 can name with the subject because of the highest correlation degree, such as math grades. It is known that math grades in SEE has certain impact on those of public basic and disciplinary basic courses in university from coefficient of these three kinds of courses grades and factor 3. And English grades in SEE have the greatest impact on those of public basic course in university while minor influence on the other two kinds of courses. And grades of science-integrated courses have close impact on those of public foundation and basic disciplinary courses.

\section{Implications and Conclusion}

Cluster analysis on the basic characteristics of the university course grades. In order to further study the characteristics of the correlations of grades each semester, we carry on factor analysis to students enrolled in 2010 who have no lack of performance from the first to sixth semester (excellence rate weighting of non quality curriculum performance), a total of 94 .

The results show that correlation really exists among the grades each semester, but the correlation between any two semesters is not the same. The largest values all appeared in the first each line on the right of the principal diagonal(see table 2), which shows the relevance between grades of all semester and those of the former semester is the biggest, such as correlation between the third semester and the second semester is greater than the correlation between the third semester and the first semester. In addition, The correlation between the third and fourth semester is the largest, reached about 0.8 , when a learning transition from the basic course to the professional course. Thus it is very important for college students to study hard in the third and fourth semester and emphasize on the basic curriculums. Then compute the correlation coefficient matrix characteristic value and variance contribution rate. Due to the cumulative contribution rate of the first two factors reached $81.631 \%$ and variables in the factor loading matrix has not lost. The final extraction factor is 2 , selecting the two main factors reflecting course grades. The first and second column factor load matrix shows: the first factor loading vector in five semesters has no coefficient difference. And It reflects the students' overall performance level. But the second factor load vectors shows the coefficient is negative during the first two semesters, and coefficient is positive during the next three semesters, which reflects the differences of the two periods. Draw the frequency chart by counting the number of different excellent rates, and calculate the skewness and kurtosis of excellent rate of each semester.

The kurtosis and skewness calculated is negative, which shows grades of each semester are not normal distribution, but is flat and the left side of the distribution. Kurtosis of the last three semester 
was significantly higher than that of the first two semesters, indicating that course grades are gradually differentiated. And it is more obvious after the third semester. Combined with the mean and skewness, it shows a growing trend of the increasing number of students with poor grades after the third semester. Data also illustrates this point, all the value of 1/4 points (under the four points) after the third semester are less than the first two semesters. Therefore, it is beneficial to stabilize students' scores by strengthening the performance of the third semester. And the results of factor analysis and shape analysis on university students can get a similar conclusion.

Table 2:course grades mean of Oriented college students enrolled in 2010

\begin{tabular}{|c|c|c|c|c|c|}
\hline & The first semester & The second semester & The third semester & The fourth semester & The fifth semester \\
\hline 1/4 quantile & 0.396 & 0.402 & 0.377 & 0.377 & 0.356 \\
\hline median & 0.548 & 0.557 & 0.549 & 0.561 & 0.535 \\
\hline mean value & 0.536 & 0.546 & 0.540 & 0.548 & 0.535 \\
\hline kurtosis & -0.625 & -0.711 & -0.825 & -0.918 & -0.864 \\
\hline skewness & -0.164 & -0.236 & -0.165 & -0.199 & -0.058 \\
\hline
\end{tabular}

Cluster analysis of three types of courses in University. About $1 / 4$ students have the excellent performance from cluster analysis results, while about $1 / 5$ students have relatively poor performance. Students with more than a middle grade are the most, about $30 \%$, followed by the secondary students. Further analysis on all course grades can find that it has significantly greater gap in the performance of the best and worst students than those of students in the upper middle and lower middle.And the students who have outstanding achievement have more excellent performance of basic disciplinary courses, while students with poor performance, the worse performance of basic disciplinary courses. But grades of all courses are relatively close for those above average or below average.

Thus it is difficult to master the basic knowledge of the discipline, which reflects a higher degree of discrimination in the examination results. The statistics results of the ratio of the three courses offered by all departments in P university, shows that basic disciplinary course ratio in the third semester is the highest. That is to say it is the third semester, which is the best period to embody curriculum difficulty and test students' learning status. This conclusion is consistent with the above, which the third semester is the key period of course grades differentiation. Therefore, relevant teaching department should plan rationally the curriculum according to the features. And offer necessary supervision and guidance for some difficult basic courses, which can help students overcome learning difficulties and successfully completed the transition from the public course to professional course.

\section{Acknowledgment}

This work is supported by the Educational Reform Research Subject for the Institutions of Higher Learning in Jiangxi Province (JXJG-14-22-6), the Exam and Enrollment Reform Research Subject of Jiangxi Province (1524), the Social Science and Art Research Subject of Jiangxi Province (YG2015189), the Social Science and Art Research Subject of Jiangxi Province (YG2014255),Science and technology research project department of education in jiangxi province

(GJJ151274) and also is a stage result of university party buildingProject of Jiangxi Province (JXGXDJKT.GH-201513). 


\section{References}

[1]Tomas C., Adrian F. Personality predicts academic performance: Evidence from two longitudinal university samples[J]. Journal of Research in Personality, 2003, 37: 319-338.

[2]Angus D., Elizabeth B., Karen D., John Ferguson. The relationship between personality, approach to learning and academic performance[J]. Personality and Individual Differences, 2004, 36: 1907-1920.

[3]Elchanan C., Sharon C., Donald C. B., James Bradley Jr. Determinants of undergraduate GPAs: SAT scores, high-school GPA and high-school rank[J]. Economics of Education Review, 2004, 23: 577-586.

[4]Jesse M. R.. College performance predictions and the SAT[J]. Journal of Econometrics, 2004, 121: 297-317.

[5]Urdan TC, Maehr ML. Beyond a two-goal theory of motivation and achievement: a case for social goals[J].Review of Educational Research,1995,65:213-243.

[6]Vande Walle DM. Development and validation of a work domain goal orientation instrument [J].Education and Psychological Measurement.1997, 57: 995-1015.

[7]Wentze K R. Adolescent classroom goals, standards for performance, and academic achievement: An inter-actionist perspective[J].Journal of Educational Psychology, 1989, 81:131-142. 